\title{
A HISTÓRIA COMO FERRAMENTA DE ENSINO DOS NÚMEROS
}

\author{
THE HISTORY AS A TEACHING TOOL OF THE NUMBERS
}

\author{
Antonio Rodrigues Junior ${ }^{1}$; Marcos Lübeck ${ }^{2}$
}

\begin{abstract}
RESUMO
Neste artigo apresentamos reflexões a partir de uma pesquisa realizada no âmbito de um Trabalho de Conclusão de Curso na área de história da matemática, defendido na forma de Monografia no Curso de Licenciatura em Matemática, da Universidade Estadual do Oeste do Paraná (UNIOESTE), campus de Foz do Iguaçu/PR, e que teve como motivação investigar acontecimentos e singularidades relacionadas com a história dos números. Para tanto, sustentados metodologicamente em uma investigação histórico-bibliográfica, estudamos publicações da área, destacando considerações, fatos e excertos, assumindo a história como uma ferramenta de ensino. Nessa perspectiva, a historiografia foi adotada como o suporte principal, a qual apresenta os números e como as suas representações foram sendo concebidas ao perpassar diferentes culturas, enfatizando, em particular, a necessidade que os seres humanos tiveram para contar e para representar as quantidades a partir dos seus respectivos cotidianos, desenvolvimentos que foram fundamentados com a contribuição de muitas civilizações. Sobre a história dos números propriamente dita, percorremos diversos referenciais com o desígnio de mostrar neste caminho que os professores de matemática tem um importante suporte para auxiliá-los no processo de ensino e aprendizagem da sua disciplina, que são os contextos históricos envolvendo os números e determinados fatos e propriedades relacionadas com os mesmos. Com isso, a possibilidade de poder se servir da história da matemática é fundamental, tanto para os professores quanto para os estudantes, sobretudo neste momento, quando mudanças educacionais significativas estão sendo previstas, experimentadas e praticadas, pautadas agora em documentos e legislações reformuladas, com bases remodeladas e diferentes referenciais curriculares.
\end{abstract}

Palavras-chave: História da Matemática; Educação Matemática; História dos Números.

\footnotetext{
ABSTRACT

In this paper we present reflections from a research carried out within the scope of a Course Conclusion Work in the area of history of mathematics, defended in the form of a Monograph in the Mathematics Degree Course, at the State University of Western Paraná (UNIOESTE),

${ }^{1}$ Licenciado em Matemática pela Universidade Estadual do Oeste do Paraná (UNIOESTE). Mestrando no Programa de Pós-Graduação em Ensino da Universidade Estadual do Oeste do Paraná (UNIOESTE), Foz do Iguaçu, Paraná, Brasil. Endereço para correspondência: Rua Barão da Serra Negra, 1139, Morumbi, Foz do Iguaçu, Paraná, Brasil, CEP: 85.858-430. E-mail: juniorarjrodri3@ gmail.com.

ORCID iD: https://orcid.org/0000-0002-1057-8688.

${ }^{2}$ Doutor em Educação Matemática pela Universidade Estadual Paulista (UNESP). Docente no Curso de Matemática e no Programa de Pós-Graduação em Ensino da Universidade Estadual do Oeste do Paraná (UNIOESTE), Foz do Iguaçu, Paraná, Brasil. Endereço para correspondência: Avenida Garibaldi, 2100, Jardim Lancaster, Foz do Iguaçu, Paraná, Brasil, CEP: 85.869-012. E-mail: marcos.lubeck@ unioeste.br.

ORCID iD: https://orcid.org/0000-0001-6787-7083.
} 
campus from Foz do Iguaçu/PR, whose study was motivated to investigate events and singularities related to the history of numbers. For that, supported methodologically in a historical-bibliographic investigation, we studied publications of the area, highlighting considerations, facts and excerpts assuming the history as a teaching tool. In this perspective, the historiography was adopted as the main support, the which presents the numbers and how their representations were conceived when permeated different cultures, emphasizing in particular the need that human beings had to count and to represent the quantities from of their daily lives, development that were based on the contribution of many civilizations. About the history of numbers, we went through several references with the objective of showing in this script that mathematics teachers have an important support to assist them in the process of teaching and learning their discipline, which are the historical contexts involving numbers and certain facts and property related to them. As a result, the possibility of being able to use the history of mathematics is fundamental, both for teachers and students, especially at this moment when significant educational changes are being foreseen, experienced and practiced, centered on reformulated documents and legislation, based on remodeled and different curriculum references.

Keywords: History of Mathematics; Mathematics Education; History of Numbers.

\section{Introdução}

As diferentes representações dos números que conhecemos não surgiram do dia para a noite e nem são devidas a um único indivíduo ou povo, haja vista que os números sobrevém da necessidade que muitas pessoas tiveram para contar, desde os tempos mais remotos, quando eram usadas pedras, entalhes em madeiras, ossos ou cerâmicas, nós em cordas e partes do corpo humano para quantificar, como destaca Ifrah (2005). Por meio deste imperativo a humanidade começou a formalizar, segundo expõe Gundlach (1992), os conceitos de enumeração, numeração e número, e nesse desenvolvimento a contagem de objetos de uma coleção passou a ser representada por desenhos ou símbolos.

Historicamente, esse percurso envolveu a contribuição de diversas culturas, e as formas que utilizamos para representar os números se devem a várias delas. Com efeito, a historiografia mostra que esta foi uma construção coletiva, e vemos em referências da história da matemática, nomeadamente, Boyer (1996), Cajori (2007), Eves (2004), Katz (2010) e Roque (2012), que os povos antigos mais destacados nessa estruturação foram os egípcios, sumérios, babilônicos, romanos, gregos, hebreus, maias, incas, chineses, japoneses, hindus e árabes. Dos dois últimos, herdamos a essência de um importante sistema decimal que fora completado e que é amplamente utilizado mundo afora.

Destacamos, contudo, que os números não foram utilizados apenas na contagem. Estes eram empregados igualmente na mitologia, sendo associados a divindades, o que significa que possuem um importante papel místico e religioso, sendo arrolados com forças benéficas ou maléficas, isto é, a história dos números não só traz contribuições 
para a sociedade na sua forma matemática como também está associada ao misticismo e a religiosidade, como discutem alguns autores, tais como Ferriz (1977), Heyss (2007), Lübeck, Lübeck e Bellei (2007), Mendes (2006), Sabellicus (1977) e Stewart (2016).

Dessa forma, apresentar acontecimentos interessantes e curiosos na sala de aula pode proporcionar um melhor entendimento dos alunos no que diz respeito a dimensão histórica dos assuntos envolvidos, despertando o interesse dos mesmos, motivando-os a estudar e a conhecer distintas experiências, como bem realçam Freire (2009), Hassman (2004), Mendes (2015), Mendes, Fossa e Valdés (2006) e Miguel e Miorim (2011).

Além do mais, como em Rodrigues Junior (2019), defendemos que a história da matemática é uma importante ferramenta para a educação matemática, pois por meio dela os professores têm uma oportunidade de expor aos seus alunos como, quando, onde e porque surgiram certas ideias e com quem estas se desenvolveram. Mas, para esse fim, os professores devem se dispor à uma abordagem histórica no ensino da matemática.

Com isso, é possível mostrar às crianças e jovens que a matemática não surgiu totalmente pronta, e tentar superar a noção de que a mesma é difícil e para poucos. Os professores, ao aproveitarem a ferramenta histórica para explicar um algoritmo, por exemplo, tem em mãos um notável instrumento que oferece grandes possibilidades para contextualizar os objetos matemáticos e facilitar a construção desse conhecimento.

Nesse ponto destacamos que, em se tratando de um estudo sobre a história dos números, a metodologia adotada segue os preceitos da pesquisa histórico-bibliográfica, que de acordo com Fiorentini e Lorenzato (2006), Marconi e Lakatos (2007) e Severino (2010), objetiva estudar fontes confiáveis e fazer pesquisas em documentos e materiais diversos, como livros, artigos, teses etc., com o intento de entrar em contato com o que já foi registrado sobre um determinado assunto. Essa metodologia permite que um tema, mesmo não sendo inédito, possa ser enfocado sob várias perspectivas, a partir de dados compilados por outros pesquisadores e que encontram-se registrados e à disposição.

Assim, o objetivo deste artigo é mostrar aos professores de matemática que estes têm uma importante ferramenta para auxiliá-los no processo de ensino e aprendizagem da sua disciplina, a saber, os contextos históricos que envolvem os números. Para tanto, expomos considerações sobre a matemática e o seu ensino, listando fatos curiosos sobre certos números e as relações deles com a história da matemática, enfatizando seu valor para a educação matemática, respaldados em referências desse campo de conhecimento. 


\section{A matemática e seu ensino}

A matemática é muito importante para o ser humano, tanto que é uma ciência considerada indispensável para a nossa sobrevivência. E ao falar disso, naturalmente, lembramos dos números, pois os mesmos se fazem presentes em quase tudo na nossa vida, desde quando nascemos, onde vivemos, até quando morremos; dos documentos e registros aos códigos postais, dos identificadores telefônicos aos valores das nossas contas à pagar.

Realmente, os números estão ligados a saga humana desde tempos longínquos, e mais do que qualquer tema, é um assunto assaz significativo para estabelecer conexões entre o conhecimento presente e a origem histórica dos conteúdos matemáticos, algo de importância destacada nas unidades temáticas que tratam dos números e que podemos ler na Base Nacional Comum Curricular (BNCC) e no Referencial Curricular do Paraná (RCP), como apontam Brasil (2017) e Paraná (2018), respectivamente.

Nesse ponto vale realçar uma competência matemática relacionada na BNCC e a seção temática que engloba os números, as quais mencionam a importância de

\footnotetext{
Reconhecer que a matemática é uma ciência humana, fruto das necessidades e preocupações de diferentes culturas, em diferentes momentos históricos, e é uma ciência viva, que contribui para solucionar problemas científicos e tecnológicos e para alicerçar descobertas e construções, inclusive com impactos no mundo do trabalho. [...]. A unidade temática números tem como finalidade desenvolver o pensamento numérico, que implica o conhecimento de maneiras de quantificar atributos de objetos e de julgar e interpretar argumentos baseados em quantidades. [...]. No estudo desses campos numéricos, devem ser enfatizados registros, usos, significados e operações (BRASIL, 2017, p. 267-268).
}

A esse respeito, reforçamos a ideia da matemática ser uma ciência humana, em constante desenvolvimento, vívida, que comumente lida com situações reais no tempo e no espaço, sendo decorrente de processos cumulativos que perpassam toda a história das civilizações e com implicações e reflexos importantes na vida das pessoas. Contudo, seu saber/fazer não pode olvidar as suas origens e para que surgiu, ou seja, para atender à demandas humanas, pois ela é, igualmente, uma manifestação humana. Nestes termos, a educação matemática precisa sim avivar apontamentos, usos e significados, como anota a BNCC no que concerne o ensino dos números e suas operações. No tocante ao RCP,

Como fundamentação teórico-metodológica, assume-se, nesse documento, a educação matemática como uma área de pesquisa que possibilita ao professor balizar suas práticas educativas em uma ação que leva em consideração, além dos conhecimentos matemáticos, aspectos cognitivos, as questões sociais, 
culturais, econômicas, políticas, entre outras. As tendências metodológicas dessa área [...] são estratégias que permitem desenvolver os conhecimentos matemáticos (PARANÁ, 2018, p. 810).

Quanto a isso, entendemos que a educação matemática deve sempre consagrar a diversidade, seja metodológica, sociocultural e material, em todos os níveis de ensino. Porém, a maneira como a matemática é trabalhada nas escolas, normalmente, pauta-se apenas nos livros didáticos, os quais servem como auxílio principal tanto para os alunos quanto para os professores. Nesse sentido, “embora o livro didático seja um recurso importante no processo de ensino e aprendizagem, ele não deve ocupar o papel dominante nesse processo" (BRASIL, 2013, p. 13). Consequentemente, compete aos professores serem diligentes e não tomar o livro didático como o único suporte para as aulas, pois qualquer recurso e informação adicional é sempre bem vinda e desejável.

Aliás, "a matemática que lemos nos livros já foi produzida há muito tempo e reorganizada inúmeras vezes. Entretanto, não se trata de um saber pronto e acabado" (ROQUE, 2012, p. 31). Por isso, precisamos mostrar aos estudantes que a matemática não surgiu de forma cabal e findada, e que ainda está em desenvolvimento. Por certo,

[...] a história oferece as informações necessárias para: 1) a compreensão da realidade da vida cotidiana e sua interação social; 2) a compreensão da linguagem e do conhecimento cotidiano estabelecido nos períodos em que os tópicos matemáticos se desenvolveram e se formalizaram da maneira como os conhecemos atualmente (MENDES, 2015, p. 128).

Daí a importância de estudar a história para ensinar, em quaisquer que sejam as fontes, como artigos, livros, teses, dissertações, monografias, vídeos etc., que abordam a história da matemática, não nos atendo apenas a um livro didático, nem a uma tendência metodológica ou uma estratégia de ensino. Essa postura indica que a contextualização no ensino da matemática, por meio da história, é um caminho auspicioso a julgar pelas informações que oferece, as quais potencializam o acesso aos saberes acumulados ao longo dos tempos e à sua compreensão, promovendo o avanço cultural da humanidade, tal como mostram determinadas relações entre os números e a história da matemática.

\section{Os números e a história da matemática}

Quando falamos em números, a primeira coisa que nos vem à cabeça é a forma para a representação dos mesmos. Entretanto, o que são números? O que é um número? A pergunta é simples, mas a sua resposta está longe de ser. Isso porque, diferentemente de saber contar ou usar números, definir de maneira lógica e axiomática, ou matemática, 
o que eles são não é uma tarefa fácil, especialmente na educação básica, pois "um número não é algo que se possa mostrar a alguém no mundo físico. [Ele] é uma abstração, um conceito mental humano - derivado da realidade, mas não verdadeiramente real" (STEWART, 2016, p. 23, grifo do autor).

Com efeito, a noção de número é uma das mais importantes dentro da disciplina de matemática e está presente no alicerce do seu ensino. Comumente dizemos na escola que os números podem ser classificados como naturais, inteiros, racionais, irracionais, reais, complexos; podem ser pares ou ímpares; ou quadrados, triangulares, poligonais; e que podem ser perfeitos, amigos, primos etc., podendo muitos números pertencer a mais de um conjunto desses. No entanto, não dizemos como define Russell (2006, p. 31), que "um número será um conjunto de classes tais que quaisquer duas são equipotentes entre si e nenhuma fora do conjunto é equipotente a qualquer uma de dentro do conjunto", ou, ainda, que "um número é qualquer coisa que seja o número de alguma classe", porque esta definição, rigorosa e num viés filosófico-matemático, necessita de conhecimentos de um nível superior que estão além dos requeridos na educação básica.

Apesar disso, independentemente de qualquer definição, os números nos ajudam não apenas no processo de contagem, mas auxiliam a compreender os fenômenos que acontecem a nossa volta, ou seja, estão presentes no nosso dia-a-dia e tornaram-se tão comuns que quase nem pensamos sobre eles, mas estes representam muito mais do que um conjunto de classes ou a forma de quantificar o que existe ao redor, como podemos ver em muitos episódios interessantes sobre os números.

Além do mais, os números também são fundamentais no ensino, e de acordo com as Diretrizes Curriculares da Educação Básica do Paraná (DCE), estas dizem que,

Quanto às expectativas de ensino e de aprendizagem desse Conteúdo Estruturante, espera-se que no Ensino Fundamental os alunos compreendam: - o sistema de numeração decimal e o conceito de notação científica;

- os conceitos da adição, subtração, multiplicação, divisão, potenciação e radiciação de números pertencentes aos conjuntos dos naturais, inteiros, racionais, irracionais e reais e suas propriedades;

- o conceito de razão e proporção, regra de três, porcentagem, frações dos números decimais e as suas operações. [...].

No Ensino Médio, há a necessidade de aprofundar o estudo dos números, de modo a ampliar o conhecimento e domínio deste conteúdo para que o aluno:

- compreenda os números complexos e suas operações;

- conceitue e intérprete matrizes e suas operações;

- conheça e domine o conceito e as soluções de problemas que se realizam por meio de determinante;

- identifique e realize operações com polinômios; 
- identifique e resolva equações, sistemas de equações e inequações [...] (PARANÁ, 2008, p. 51-52).

Conforme estas diretrizes, podemos perceber que os números regem boa parte da matemática fundamental e as suas operações. Efetivamente, os números são como uma ponte que une o concreto à sua respectiva correspondência abstrata, pois como afirma Roque (2012, p. 39), “contar é concreto, mas usar um mesmo número para expressar quantidades iguais de coisas distintas é um procedimento abstrato”. Nesse ínterim, a história da matemática se torna muito importante, tanto para os professores quanto para os estudantes, pois numa aula de matemática não devemos apenas passar informações, mas explicar o desenvolvimento dos conceitos.

Segundo as DCE, ainda,

A história deve ser o fio condutor que direciona as explicações dadas aos porquês da matemática. Assim, pode promover uma aprendizagem significativa, pois propicia ao estudante entender que o conhecimento matemático é construído historicamente a partir de situações concretas e necessidades reais (PARANÁ, 2008, p. 66).

Podemos ver aqui que a história da matemática e a sua interpretação tornam-se imprescindíveis na educação matemática, pois ela é essencial nas discussões sobre a realidade. Além disso, a história da matemática pode ser empregada como estratégia para abordar e motivar o ensino de conceitos matemáticos. E mais, D’Ambrosio (1996) diz que a história da matemática é fundamental para o estabelecimento da matemática como elemento cultural, inverso ao modo mecanicista de considerá-la como algo exato, acabado e alheio as alterações e influências humanas.

Ao conhecerem a história da matemática, os alunos passam a percebê-la como uma ciência desenvolvida pela humanidade, passível de erros e construída a partir de muitas tentativas em solucionar problemas cotidianos, problemas esses que, vistos por um viés histórico, metódico e científico, podem levá-los à compreensão da necessidade e do surgimento de diferentes conteúdos matemáticos que existem. Realmente, "na falta de compreensão dos métodos e procedimentos científicos, o caráter aparentemente fortuito dos descobrimentos que faz a ciência, estimula o público a adotar para com ela uma atitude malsã, cheia de desconfiança. Sempre se teme o que não se compreende" (FERRIZ, 1977, p. 183). E para superar essa incompreensão, pesquisamos e educamos.

Além disso, em termos educacionais, 
O principal objetivo é que a história da matemática contribua para que professores e estudantes entendam e superem as fraturas epistemológicas surgidas no desenvolvimento da compreensão matemática, ou seja, trata-se de buscar na história os porquês matemáticos de modo a utilizá-los na superação dos obstáculos cognitivos no desenvolvimento da matemática escolar (MENDES; FOSSA; VALDÉS, 2006, p. 90).

Nesse quesito, tanto Miguel e Miorim (2011) quanto Mendes, Fossa e Valdés (2006) citam propostas e apresentam provocações sobre o uso da história da matemática enquanto ferramenta - metodologia, recurso ou agente - de ensino e aprendizagem para a educação matemática. À educação básica, vale listar algumas razões reunidas por estes autores para a história adentrar esse meio. Dentre todas, ressaltamos que a história incita estudar e aprender matemática; humaniza-a; desmistifica-a; ressignifica-a; transforma sua representação; conscientiza; apresenta percepções; levanta possibilidades; aponta aspectos práticos, teóricos e conceituais; revisita diferentes culturas; explica seu papel nas sociedades e a sua serventia para a vida das pessoas em todas as ocasiões.

Por razões como essas que os professores precisam despertar nos estudantes um aspecto investigativo, para que eles busquem alternativas para resolver seus problemas, propiciando que os mesmos desenvolvam seu senso crítico, colaborando para que se formem cidadãos mais criativos e conscientes do seu papel na sociedade, o que faz com que tenham possibilidades evidentes de ter bom êxito na construção do conhecimento.

Outro ponto a destacar é que,

Nos últimos anos, vem se notando nos meios matemáticos preocupados com o ensino certo empenho em valorizar a história da matemática como recurso didático. As manifestações nesse sentido são diversas, culminando com a inclusão de uma disciplina específica sobre o assunto nos currículos de vários cursos de licenciatura em matemática. Essa tendência nos parece sobre maneira auspiciosa, sendo de lamentar apenas não ter ocorrido bem antes. A matemática desde os seus primórdios entrelaça-se tão intimamente com a história da civilização, sendo uma das alavancas principais do progresso humano, que sua história é não só altamente motivadora em termos de ensino como também rica em aspectos culturais (DOMINGUES, 1992, p. 1).

Sendo assim, a história da matemática pode ser empregada como estratégia para abordar e motivar o ensino de conceitos matemáticos, pois é carregada de cultura. Mas, um detalhe importante é que "[...] a história da matemática, se tratada como um assunto específico ou conteúdo, seria insuficiente para contribuir para o processo de ensino e aprendizagem da matemática" (MIGUEL; MIORIM, 2011, p. 16). Entretanto, a articulação entre conteúdos matemáticos ensinados na escola e sua história é sopesada como uma das melhores estratégias a serem implementadas em sala de aula. 
No momento em que os alunos percebem o surgimento da matemática, a partir da busca pela resolução de problemas cotidianos, estes conhecem as preocupações que envolveram os povos, em diferentes momentos históricos. Isto proporciona estabelecer relações entre processos matemáticos do passado e presente, o que faz compreender que os saberes ensinados na escola não se originaram sem um propósito, sem um porquê.

E uma forma de fazer isso é utilizar episódios que estimulem e, ao mesmo tempo, despertem a curiosidade dos estudantes. Diante de um mundo globalizado como o nosso, é impensável que esse sentimento não seja aflorado pelo mundo escolar, acadêmico e na sociedade, haja vista que a curiosidade possibilita atitudes mais saudáveis, pois fomenta a pesquisa, o estudo e a descoberta (HASSMANN, 2004).

Sobre a percepção de curiosidade, assumimos

A curiosidade como inquietação indagadora, como inclinação ao desvelamento de algo, como pergunta verbalizada ou não, como procura de esclarecimento, como sinal de atenção que sugere alerta e faz parte integrante do fenômeno vital. Não haveria criatividade sem a curiosidade que nos move e que nos põe pacientemente impacientes diante do mundo que não fazemos, acrescentando a ele algo que fazemos (FREIRE, 2009, p. 32).

Realmente, a história traz consigo muitas curiosidades interessantes relacionadas aos números e os professores podem utilizá-las para auxiliar no ensino. Isso representa muito, porque, na verdade, "saber que ensinar não é transferir conhecimento, mas criar as possibilidades para a sua própria produção ou a sua construção" (Ibidem, p. 47), é algo crucial para a educação matemática, e na era do conhecimento globalizado, não cabe mais uma proposta de ensino e aprendizagem enlatada, padronizada ou parcial.

Logo, os professores precisam dialogar mais com seus alunos, aguçando a sua curiosidade, fazendo com que estes sintam interesse pelo saber, ou seja, ao descobrir os porquês de determinados conteúdos, estes fiquem curiosos com as descobertas, e que estas os levem a procurar por significados mais profundos, questionando e usando todas as ferramentas possíveis e imagináveis para que possam ver além do que lhe é proposto. E um caminho é apresentar fatos sobre os números, quando este for o assunto estudado.

\section{Fatos sobre os números}

Os números que nós conhecemos se devem a muitos povos. Dentre os que mais se destacam na historiografia estão os egípcios, sumérios, babilônicos, gregos, hebreus, romanos, incas, maias, chineses, japoneses, hindus e árabes. Contudo, um dos sistemas 
de numeração mais conhecido é o indo-arábico, o qual traz os símbolos 1, 2, 3, 4, 5, 6, $7,8,9,0$ com os quais podemos escrever qualquer número que se queira, sendo este um sistema posicional completo e que se dispõe em agrupamentos de dez em dez.

Esse sistema foi disseminado na época medieval, adentrando na Europa entre 476 e 1453, e popularizado em especial pelos matemáticos ligados às escolas religiosas ou universidades e pelos comerciantes e, a partir de então, se tornou o mais difundido e empregado em todo o mundo. Nesse sentido, "no que se refere à história é costume designar a queda de Roma em 476 como o começo da Idade Média, e a queda de Constantinopla perante os turcos em 1453 como o fim" (BOYER, 1996, p. 168).

Dito isso, ao fazermos um estudo histórico sobre os números, a questão inicial que se coloca é: Por onde começar? De fato, tudo começa com pessoas da Pré-História, com suas ideias de grandezas e medidas, formas e códigos. Começamos, assim, com as ideias de número e os processos de contagem, pois foi a partir destes que boa parte da matemática se desenvolveu, todavia essa história só pode ser contada porque existem remanescentes materiais, técnicos e artísticos (como ossos, pedras, madeiras, tabletes, pergaminhos, livros, jogos, enigmas etc.), elementos essenciais para que possamos falar de algo tão remoto. A esse respeito, olhando os remanescentes, implica ressaltar que

[...] o exemplo histórico nos ajuda a compreender em que sentido o número pode ser entendido como uma abstração. A palavra "abstrair" designa justamente que certas propriedades foram isoladas, separadas dos exemplos concretos em que estão presentes [...]. O conceito de número é abstrato, mas não porque pode ser representado por um símbolo, e sim porque pressupõe abstrair a natureza particular dos seres em uma coleção. A abstração torna possível um conceito de número que poderá, então, receber um nome e ser representado por um símbolo. Assim, em diferentes processos de contagem, ainda que o estabelecimento de correspondência seja equivalente, os nomes dos números podem diferir (ROQUE, 2012, p. 87-88).

Essa prerrogativa de, em certo sentido, poder voltar no tempo, revirar a memória cultural da humanidade e encontrar exemplos é extremamente educativa, especialmente no que se refere ao entendimento dos números, pois estes são fundamentais para a vida das pessoas, tanto é que são sopesados indispensáveis à sobrevivência e transcendência. De fato, ninguém pode viver integrado socialmente sem seus documentos e respectivos números de identificação. Logo, precisamos estabelecer uma conexão plausível sobre os números e a sua origem, razão pela qual estamos estudando fatos relevantes do ponto de vista da história e da educação matemática. Não por acaso, 
Nos primórdios da história dos números [...] observaram-se curiosas propriedades de certos números, averiguaram-se notáveis relações entre números aparentemente não relacionados, foram utilizadas estranhas analogias entre números e configurações geométricas e esta insaciável busca continuou, século após século até hoje em dia [...] (FERRIZ, 1977, p. 122).

Porém, os números não foram utilizados apenas para contar, medir ou instigar a pesquisa em matemática, ao contrário, estes foram consagrados também à religiosidade, sendo ligados a divindades, o que significa que tinham uma função mística, integrando nisto forças terrenas e etéreas, associação que, por vezes, ainda podemos perceber. Isto posto, a história dos números não só apresenta contribuições em forma matemática, mas em outras configurações, como as associadas com o misticismo.

Assim, listamos agora alguns fatos históricos e matemáticos, bem como registros místicos que se referem a determinados números, conforme a história, a matemática, a numerologia, o esoterismo, o tarô e a gematria. Estes excertos trazem apenas amostras de um universo numérico e de fatos muito mais amplo dos que os aqui descritos.

O número 1 simboliza a unidade, podendo ser representado por uma barra, um ponto, a letra alfa/alef, um cravo, um nó... Na matemática expressa a ideia da unicidade. Aliás, "o menor número inteiro positivo é 1. Ele é a unidade indivisível da aritmética: o único número positivo que não pode ser obtido pela soma de dois números positivos menores. [...]. O número 1 é onde começamos a contar" (STEWART, 2016, p. 31). Para Euclides (2009, p. 269), a "unidade é aquilo segundo qual cada uma das coisas existentes é dita uma. E número é a quantidade composta de unidades". O 1 significa a força criadora de tudo; pode ser o sol, um deus, a origem, um centro. Por vezes, o "um não se considera como número, [pois] não pode ser figura, simbolicamente é um centro indeterminado de um círculo onde a circunferência não está em nenhuma parte" (FERRIZ, 1977, p. 151). Os fenícios, gregos e hebreus o representavam por meio da primeira letra do seu alfabeto. Também, “o número 1 representa o homem de pé e sua verticalidade é como um sinal distintivo da espécie humana [...]. É o signo cabalístico da geração, da fecundação" (MENDES, 2006, p. 20). Para muitas crenças, simboliza a unidade, o princípio de tudo, o número gerador. Aqui, "pelo fato de ser o primeiro, e de dar origem aos outros números, o 1 também é relacionado à objetividade e à realização" (MENEGHETTI, 2017, n.p.). Assim, é a partir dele e com ele que tudo começa.

O número 2 é um separador e representa conceitos como dualidade, paridade, dobro, metade, potência quadrada, notação binária... Mesmo, “[...] o 2 é considerado o 
símbolo de oposição, de conflito e de reflexão. [...]. É a cifra de todas as ambivalências e dos desdobramentos. É primeira e mais radical das divisões [...], aquela de que decorrem todas as outras" (MENDES, 2006, p. 21). Ainda, “o número 2 refere-se ao movimento da vida, que possui ação e reação; força centrípeta e centrífuga; o bem e o mal; a sombra e a luz [...] expansão e retração [...] contração e distensão" (Ibidem, p. 23). Igualmente, "o dois não pode ser figura, seria o diâmetro de um círculo onde a circunferência não existiria, quer dizer, uma linha reta de direção indeterminada e de longitude indefinida que corta o plano em duas zonas" (FERRIZ, 1977, p. 152). Dois é a dimensão do plano na geometria. O 2 é o primeiro número par. "Um número par é o que é dividido em dois" (EUCLIDES, 2009, p. 269), e "qualquer número inteiro que seja múltiplo de 2 é par" (STEWART, 2016, p. 36). É o menor e único número primo par. "Um número primo é o medido por uma só unidade" (EUCLIDES, 2009, p. 269). Vale ressaltar que todo número natural é classificado como sendo um primo ou composto. Se for obtido pela multiplicação de dois números é composto; e um número não podendo ser obtido dessa maneira é primo (GUNDLACH, 1992). Aliás, "o teorema fundamental da aritmética diz que os números primos são os tijolos de construção a partir dos quais os outros inteiros são formados multiplicativamente" (EVES, 2004, p. 622).

O número 3 representa a junção da unidade com a dualidade, formando assim a trindade, ou trio, uma terna, a tríade, a potência cúbica... "É o signo da Potência, do Ser Absoluto e chama-se o "Número Potencial"” (FERRIZ, 1977, p. 152). Três é a dimensão do espaço, e "a sua imagem geométrica pode ser representada pelo triângulo equilátero. Remete-nos à trindade dos cristãos que se reúne em um só Deus [Pai, Filho e Espírito Santo]. O 3 refere-se também aos reinos da natureza - animal, vegetal e mineral" (MENDES, 2006, p. 24). Para os gregos antigos e romanos ele tinha um poder oculto, inspirando enigmas, superstições, crendices, provérbios e ditados populares. É ainda um número ímpar. Um número pode ser par ou ímpar, números pares são divisíveis por 2, e números ímpares não são. Daí “um número ímpar é o que não é dividido em dois, ou [o] que difere de um par por uma unidade" (EUCLIDES, 2009, p. 269). E, "de acordo com os chineses, é um número perfeito, que significa expressão da totalidade, da conclusão" (MENDES, 2006, p. 25). É o primeiro e menor primo ímpar. Além disso, "sete oitavos de todos os números são a soma de três quadrados" (STEWART, 2016, p. 57).

Agora, "as simbolizações relacionadas ao número 4 se ligam às do quadrado e da cruz, significando a solidez, o tangível, o sensível, a plenitude, a universalidade e a 
totalização. Referem-se às operações básicas da aritmética (adição, subtração, divisão e multiplicação) [...]” (MENDES, 2006, p. 25). Antes, “o quatro dá conta da dualidade ativa, é o círculo posto em rotação pela cruz. Quadrado de dois é a primeira exaltação da dualidade [...]. Sabe-se, também, que o tetraedro (sólido de quatro lados) engendra o cubo, o octaedro, o dodecaedro e o icosaedro" (FERRIZ, 1977, p. 152). Além disso, “o primeiro quadrado perfeito [...] é 4. Todo mapa no plano pode ser colorido com quatro cores de modo que regiões adjacentes tenham cores diferentes. Todo número inteiro positivo é a soma de quatro quadrados" (STEWART, 2016, p. 67). Em outros lugares, 4 são os naipes do baralho, os pontos cardeais, as fases da lua, as estações do ano, os quatro elementos - terra, água, fogo e ar -, assim como os estágios da vida humana infância, juventude, maturidade e velhice. Para os árabes, servia de padrão em nove agrupamentos de 4 valores para a análise da beleza (MENDES, 2006). Já na China é considerado o número do azar, mas essa crença é associada a qualquer número derivado dele e todas as suas variações. São 4 também os quadrantes do círculo trigonométrico.

O número 5 representa a menor hipotenusa numa terna pitagórica; ainda, está associado a harmonia pentagonal dos pitagóricos. Na geometria há exatamente 5 sólidos regulares - tetraedro, cubo, octaedro, dodecaedro e icosaedro -, "digo, então, que exceto as cinco ditas figuras não será construída outra figura, contida por equiláteras e equiângulas iguais entre si" (EUCLIDES, 2009, p. 592). Aliás, “estes cinco sólidos platônicos simbolizam, na mitologia antiga, o Conhecimento total e integral que comporta a Identificação com o Único e onde a Criação revelou-se nela mesma" (FERRIZ, 1977, p. 152). Além disso, o 5 significa “[...] a união ou o número do casamento, porque se constitui a partir da soma do primeiro número par e do primeiro número ímpar. [...] e por ser o termo central da sequência dos nove primeiros números, o 5 é considerado o centro da harmonia e do equilíbrio" (MENDES, 2006, p. 27). Na China, o 5 é o número do centro, estando, pois, na casa central do mais antigo quadrado mágico conhecido de nove casas para números de 1 a 9 . Antes, 5 são os dedos de cada mão e de cada pé; e 5 são os nossos sentidos. Outro fato é que este número "é o número fundamental das sociedades secretas" (MENDES, 2006, p. 27).

O número 6 é um símbolo de perfeição, considerado na matemática um número perfeito, pois a soma de seus divisores próprios resulta nele mesmo. Aliás, “um número perfeito é o que é igual às suas próprias partes" (EUCLIDES, 2009, p. 270). O seis representa na natureza os pontos cardeais com o nadir e o zênite. Na geometria expressa 
perfeição por meio do hexágono regular inscrito numa circunferência e corresponde ao número de pontas do polígono na estrela hebraica. “A origem da criação também está relacionada com o número 6 , pois, de acordo com a Bíblia, 6 foram os dias da criação e foi no sexto dia que o homem foi criado, conforme o Gênesis” (MENDES, 2006, p. 29). De fato, "Deus viu que tudo o que havia feito era muito bom. A noite passou, e veio a manhã. Esse foi o sexto dia" (BÍBLIA, 2000, p. 3). Além disso, “a Bíblia aponta o sexto dia da semana como o dia da morte de Cristo, na cruz” (MENDES, 2006, p. 29).

O número 7 é bem significativo, pois "o 7 sempre esteve ligado aos saberes da tradição milenar, geralmente por estar relacionado com fatos ou acontecimentos que marcaram a vida da humanidade no planeta" (MENDES, 2006, p. 29). Na mitologia grega, era consagrado à deusa Minerva e ao deus Apolo. Na natureza, sete são as cores do arco-íris e os dias que duram uma fase da lua. São sete os dias da semana. Na Bíblia é um número recorrente. São sete os dias da Criação, sendo que "no sétimo dia Deus acabou de fazer todas as coisas e descansou de todo o trabalho que havia feito. Então abençoou o sétimo dia e separou como um dia sagrado" (BÍBLIA, 2000, p. 3). Sete são as maravilhas do mundo antigo, os pecados capitais, os arcanjos do céu, as notas musicais; e sete são os palmos de fundura de uma cova. Também, "é o menor número de cores necessárias para colorir todos os mapas num toro de maneira que regiões adjacentes tenham cores distintas" (STEWART, 2016, p. 102). Por fim, "o 7 é o único número, entre os primeiros dez, que não é (aritmeticamente) nem múltiplo, nem divisor de qualquer número da sequência de 1 a 10" (MENDES, 2006, p. 30).

O número 8 na matemática é o primeiro cubo não trivial, sendo o único cubo não trivial da sequência de Fibonacci, "[...] na qual cada número após os dois primeiros [1 e 1] é a soma dos dois que o precedem" (STEWART, 2016, p. 118). Oito também são os lados do octógono que se constrói a partir de um círculo dividido em quatro partes iguais inscrito num quadrado. E quando está na horizontal, lembra o símbolo do infinito $(\infty)$. O oito, segundo a tradição milenar antiga, "era o símbolo da igualdade humana. [...] o número 8 é considerado, universalmente, o número do equilíbrio cósmico, pois é o número das direções cardeais, ao qual se acrescenta o das direções intermediárias: o número da rosa-dos-ventos, da torre dos ventos ateniense" (MENDES, 2006, p. 31).

O número 9 está no fim de um ciclo de contagem e início de outro. Por isso, "a função de reduzir a nada está, pois, inteiramente contida neste número e seus múltiplos” (FERRIZ, 1977, p. 153). Aliás, “o número 9 é considerado o 'zero' de um ciclo superior 
de numeração, pois ele representa o começo e o fim [...] (o alfa e o ômega). Para muitos sábios antigos, esse era o emblema da matéria que é sempre variável, mas nunca destruída” (MENDES, 2006, p. 33). Outrossim, 9 é o número de casas do menor quadrado mágico não trivial. Os "quadrados mágicos são arranjos de números [...] de modo que cada linha, cada coluna e ambas as diagonais tenham a mesma soma. [...]. O menor quadrado mágico (exceto o quadrado trivial 1x1 [...]) é um quadrado 3x3, usando os algarismos de 1 a 9" (STEWART, 2016, p. 121). Além disso, na geometria “existem nove ladrilhamentos do plano por polígonos regulares que estão dispostos da mesma maneira em cada vértice. Um retângulo de dimensões certas pode ser dividido em nove quadrados de diferentes tamanhos" (Ibidem, p. 121), são os retângulos quadriculados.

O número 10 evoca a beleza e a perfeição do universo. Representa ainda a união fraternal pelo aperto de mãos. Ainda, “o sistema decimal, que usamos para escrever os números, é baseado em 10, provavelmente porque temos dez dedos - dígitos - nas mãos" (STEWART, 2016, p. 128). Agora, "a notação atual para os números é chamada 'decimal' porque usa 10 como base numérica [...] Neste sistema os mesmos dez símbolos 0123456789 são usados para representar unidades, dezenas, centenas, milhares, e assim por diante" (Ibidem, p. 128). O 10 também é a soma dos quatro primeiros números, e “[...] expressa geometricamente a harmonia entre o ponto, a reta, o plano e o espaço" (MENDES, 2006, p. 34). Dez são os Mandamentos de Deus (BÍBLIA, 2000). No 10, lado a lado, estão o tudo e o nada, 1 e 0 , o que significa muito.

O número 11, que é um a mais do que o 10, reflete parte do simbolismo deste, pois "se o 10 traz a sensação de algo finalizado, o 11 simboliza o além, a transgressão [...] símbolo dos excessos humanos, da transgressão à ordem divina (que teria 10 Mandamentos)" (MENEGHETTI, 2017, n.p.). Onze foram os discípulos remanescente de Jesus Cristo, depois que Jesus e Judas morreram (BÍBLIA, 2000).

O número 12 é utilizado desde os tempos remotos para medições de tempo. O 12 representa a ideia de ciclo. "Desde os babilônios, o principal sistema temporal é baseado em um ano de 12 meses, e um dia de 12 horas diurnas e 12 horas noturnas. É um número que dá a dimensão do encerramento de um ciclo e início de outro" (MENEGHETTI, 2017, n.p.). Os egípcios "foram os primeiros a dividir o intervalo do nascer ao pôr-do-sol em dez horas; posteriormente acrescentaram mais duas horas, uma para a manhã e uma para o crepúsculo" (WHITROW, 1993, p. 30). Na astrologia representa os signos do zodíaco, onde os "signos são padrões dinâmicos de energia, 
doze modelos distintos com identidade própria reunidos em um todo interdependente" (COSTA, 2008, p. 39). E na religião cristã, o 12 representa o número de apóstolos de Cristo e o número de tribos de Israel (BÍBLIA, 2000).

O número 13 é considerado por muitos como um número de azar, despertando receio nas pessoas, e é conhecido em algumas culturas como a dúzia do diabo (GARY, 2018). No tarô, o 13 é o número do Arcano Maior, que representa a morte (MEBES, 1978). A cabala também destaca que há 13 espíritos do mal (ROSA, 2015). O temor ao número 13 é forte a ponto de alguns edifícios deixarem de usar o número no $13^{\circ}$ andar. Sua conotação negativa está associada, em parte, a Última Ceia feita por Jesus Cristo e seus 12 apóstolos (AZEVEDO, 2000). "Mas, apesar das ideias negativas em torno dele, o 13 pode ser considerado auspicioso. Afinal, na mitologia grega, Zeus senta-se junto a outras 12 divindades do Olimpo" (MENEGHETTI, 2017, n.p.). Da mesma forma, fazia "o rei Arthur e os doze cavaleiros da távola redonda" (SANTOLA, 2009, p. 77).

Como podemos ver, os números têm, com certeza, muita história envolvida. $\mathrm{E}$ não é só isso e nem acaba aqui. Poderíamos seguir listando mais fatos sobre os números arrolados bem como trazer informações sobre outros, como 14, 15, 16, 17, 18, 19, 20, $21,22,23,24,30,33,36,40,45,49,50,60,72,90,100,120,180,360,666, \pi, e, \varphi \ldots$, sem esquecer de falar do zero (0), mas o espaço aqui limita a nossa vontade.

\section{Considerações finais}

A história da matemática nos permite compreender melhor os conhecimentos e o porquê de se ensinar este ou aquele conteúdo matemático na escola. Sem dúvida, esta é uma ferramenta de extrema importância para o ensino e o aprendizado dos alunos e para o auxílio dos professores na medida que instiga e propicia a pesquisa e a compreensão dos desconhecidos contextos socioculturais de época e seus desdobramentos, tornando o estudo da matemática mais interessante, transdisciplinar, transcultural e holístico.

Aliás, levar aos alunos algo além daquilo que é proposto na ementa curricular faz com que os mesmos não fiquem entediados com a rotina de sala de aula e com os assuntos pré-estabelecidos. No mundo contemporâneo, a curiosidade faz frente a uma gama de informações e que se esta for instigada e bem trabalhada pode vir a estimular o conhecimento. Contudo, também há que se ter um certo cuidado com este olhar, com estes novos objetivos de estudo e investigação. 
Pensando nisso, os professores que se propõem a apresentar certos conteúdos utilizando a história como ferramenta de ensino devem ter um rigor metodológico muito firme, estudar bastante, confrontar referências, usar diferentes fontes para que os temas em estudo possam ser revividos numa perspectiva historiográfica privilegiada e que não sejam apenas narrativas soltas de acontecimentos passados. Com isso, os estudantes podem perceber que a matemática não surgiu de forma pronta e acabada, o que pode ajudar a superar a ideia de que a mesma é excelsa, complexa e para poucos indivíduos.

Assim, conhecer alguns fatos sobre os números se torna bastante agradável ao mesmo tempo em que estimula e desperta os alunos, potencializando sua aprendizagem, pois o instigar, concomitantemente, mexe com a sua curiosidade, e estes são aguçados a estudar mais e, dessa maneira, podem aprender melhor os conteúdos abarcados pela matemática, e outros também, sejam estes sobre os números ou um tema qualquer.

\section{Referências}

AZEVEDO, R. M. Vivendo e Aprendendo a Jogar: numerologia fácil. São Paulo: Outras Palavras, 2000.

BÍBLIA. Português. Bíblia Sagrada: nova tradução na linguagem de hoje. Barueri: Sociedade Bíblica do Brasil, 2000.

BRASIL. Ministério da Educação. Base Nacional Comum Curricular. Brasília: MEC, 2017. Disponível em: https://tinyurl.com/y9v7nzbc. Acesso em: 23 jul. 2020.

BRASIL. Ministério da Educação. Guia de Livros Didáticos - PNLD 2014 Matemática. Brasília: MEC, 2013.

BOYER, C. B. História da Matemática. Trad. E. F. Gomide. São Paulo: Edgar Blücher, 1996.

CAJORI, F. Uma História da Matemática. Trad. L. Coutinho. Rio de Janeiro: Ciência Moderna, 2007.

COSTA, A. M. 360 Graus: uma literatura de epifanias, o inventário astrológico de Caio Fernando Abreu. 2008. Dissertação (Mestrado em Literatura Brasileira) - Universidade Federal do Rio Grande do Sul, Porto alegre, 2008.

D’AMBROSIO, U. História da Matemática e Educação. In: FERREIRA, E. S. (org.). Cadernos CEDES, n. 40. Campinas: Papirus, 1996.

DOMINGUES, H. H. Apresentação. In: BOYER, C. B. Cálculo. Trad. H. H. Domingues. São Paulo: Atual, 1992, p. 1-2. 
EUCLIDES. Os Elementos. Trad. I. Bicudo. São Paulo: Editora UNESP, 2009.

EVES, H. Introdução à História da Matemática. Trad. H. H. Domingues. Campinas: Ed. Unicamp, 2004.

FERRIZ, D. Eu Realizei a Deus Através da Matemática. Trad. C. D. Tijerina. Porto Alegre: Humes, 1977.

FIORENTINI, D.; LORENZATO, S. Investigação em Educação Matemática: percursos teóricos e metodológicos. Campinas: Autores associados, 2006.

FREIRE, P. Pedagogia da Autonomia: saberes necessários à prática educativa. 39. ed. São Paulo: Paz e Terra, 2009.

GARY, G. The Devil's Dozen: thirteen craft rites of the old one. London: Troy Books, 2018.

GUNDLACH, B. H. Números e Numerais. Trad. H. H. Domingues. São Paulo: Atual, 1992.

HASSMANN, H. Curiosidade e Prazer de Aprender: o papel da curiosidade na aprendizagem criativa. Petrópolis: Vozes, 2004.

HEYSS, J. O Livro dos Números: a numerologia na prática e o seu simbolismo. Goiânia: Nova Era, 2007.

IFRAH, G. Os Números: a história de uma grande invenção. Trad. S. M. F. Senra. 11. ed. São Paulo: Globo, 2005.

KATZ, V. J. História da Matemática. Trad. A. Sampaio e F. Duarte. Lisboa: Fundação Calouste Gulbenkian, 2010.

LÜBECK, K. R. M.; LÜBECK, M.; BELLEI, P. A Educação Matemática e a Mística dos Números. REMATEC, Natal, ano 2, n. 3, p. 27-30, jul./nov. 2007.

MARCONI, M. A.; LAKATOS, E. M. Técnicas de Pesquisa: planejamento e execução de pesquisas, amostragens e técnicas de pesquisas, elaboração, análise e interpretação de dados. 6. ed. São Paulo: Atlas, 2007.

MEBES, G. O. Os Arcanos Maiores do Tarô: enciclopédia do ocultismo. São Paulo: Pensamento, 1978.

MENDES, I. A. História da Matemática no Ensino: entre trajetórias profissionais, epistemologias e pesquisas. São Paulo: Livraria da Física, 2015.

MENDES, I. A. Números: o simbólico e o racional na história. 1. ed. São Paulo: Livraria da Física, 2006. 
MENDES, I.; FOSSA, J. A.; VALDÉS, J. E. N. A História como Agente de Cognição na Educação Matemática. Porto Alegre: Sulina, 2006.

MENEGHETTI, D. A Simbologia Oculta por trás de 31 Números. 2017. Disponível em: https://tinyurl.com/y5g8tfng. Acesso em: 23 jul. 2020.

MIGUEL, A.; MIORIM, M. A História da Matemática: propostas e desafios. 2. ed. Belo Horizonte: Autêntica, 2011.

PARANÁ. Secretaria de Estado da Educação. Diretrizes Curriculares da Educação Básica: Matemática. Curitiba: SEED, 2008.

PARANÁ. Secretaria de Estado da Educação. Referencial Curricular do Paraná: princípios, direitos e orientações. Curitiba: SEED, 2018.

RODRIGUES JUNIOR, A. A História dos Números como Ferramenta de Ensino. 2019. Monografia (Licenciatura em Matemática) - Universidade Estadual do Oeste do Paraná, Foz do Iguaçu. 2019.

ROQUE, T. História da Matemática: uma visão crítica, desfazendo mitos e lendas. Rio de Janeiro: Zahar, 2012.

ROSA, C. Numerologia Cabalística: a última fronteira. São Paulo: ABNC, 2015.

RUSSELL. B. Introdução à Filosofia Matemática. Trad. A. J. F. Oliveira. Évora: CEHFC/EU, 2006.

SABELLICUS, J. A Magia dos Números. São Paulo: EDIÇÕES 70, 1977.

SANTOLA, E. O Livro Mestre de Feitiços e Magias. Joinville: Clube de Autores, 2009.

SEVERINO, A. J. Metodologia do Trabalho Científico. 23. ed. São Paulo: Cortez, 2010.

STEWART, I. O Fantástico Mundo dos Números: a matemática do zero ao infinito. Trad. G. Schlesinger. 1. ed. Rio de Janeiro: Zahar, 2016.

WHITROW, G. J. O Tempo na História: concepções do tempo da pré-história aos nossos dias. Trad. M. L. X. A. Borges. Rio de Janeiro: Zahar, 1993.

Recebido em: 07 / 05 / 2020

Aprovado em: 06 / 10 / 2020 